\title{
Clinical Profile of Muscular Dystrophies in Burkina Faso
}

\author{
Dabilgou AA ${ }^{*}$, Napon $\mathrm{C}^{2}$, Drave $\mathrm{A}^{3}$, Kyelem JMA ${ }^{1}$, Kambire $\mathrm{Z}^{1}$, Bhunnoo $\mathrm{A}^{1}$, Jean $\mathrm{K}^{1}$, Alao J ${ }^{4}$, Leturcq ${ }^{5}$ \\ and Urtizberea $\mathrm{A}^{6}$
}

${ }^{1}$ Neurology Department, University Hospital Yalgado Ouedraogo, Ouagadougou, Burkina Faso

${ }^{2}$ Neurology Department, University Hospital of Bogodogo, Ouagadougou, Burkina Faso

${ }^{3}$ University Hospital of Ouahigouya (Burkina Faso), Burkina Faso

${ }^{4}$ Centre Hospitalo-universitaire de la Mère et de l'enfant de Cotonou (Benin), Burkina Faso

${ }^{5}$ Service de génétique et biologie moléculaires, CHU Paris Centre - Hôpital Cochin, France

${ }^{6}$ Physiotherapy Department, Center Hospitalier Handaye, France

*Corresponding author: Dabilgou AA, Department of Neurology, University Hospital Yalgado Ouédraogo, BP 7022 Ouagadougou, Burkina Faso, Tel: 0022674384270, E-mail: dabilgouanselm@yahoo.fr

Citation: Dabilgou AA, Napon C, Drave A, Kyelem JMA, Kambire Z, et al. (2018) Clinical Profile of Muscular Dystrophies in Burkina Faso. J Neurol Neurol Disord 4(3): 301. doi: 10.15744/2454-4981.4.301

Received Date: September 7, 2018 Accepted Date: December 28, 2018 Published Date: December 31, 2018

\begin{abstract}
To describe clinical profile of muscular dystrophies in Burkina Faso, we retrospectively reviewed 17 patients who had clinical phenotypes of Muscular Dystrophy between 2004 and 2004 in the neurology Department of Yalgado Ouedraogo Teaching Hospital in Ouagadougou.

There were 16 male patients (94.1\%) and one (5.8\%) female patients. The mean age of patients was 19.82 years (6-39 years).The disease onset was characterized by motor retardation $(58,8 \%)$. The age at onset was 10 years in $52.9 \%$ of patients. The disease duration was 9.41 years. At first visit, the muscle weakness was progressive in all patients. The most neurological finding was weakness (94.1\%), Gower's sign (88.5\%) and proximal amyotrophy in 55.8\%. The mean Serum creatine kinase level was 3016.64 U/l (range 344 - 8896 U/l).

Physiotherapy (100\%), corticosteroid (41.1\%) and orthopedic management (23.5\%) were the most treatment. During the study period, the most common complications were loss of walk (23.5\%), cardiac deterioration (29.4\%) and orthopedic deterioration (41.1\%). The mortality rate was $5.8 \%$.

The present study revealed that muscular dystrophy is not an uncommon disease in Burkina Faso. We have concluded that if clinical diagnosis is possible nevertheless some difficulties exist to do muscles biopsy analysis.

Keywords: Muscular Dystrophies, Clinical Features, Burkina Faso
\end{abstract}

\section{Introduction}

Muscular dystrophies are characterized by primary damage to muscle tissue outside of any lesion of the nervous tissue. The term muscular dystrophy encompasses a range of disorders including Duchenne, Becker, congenital, myotonic, Emery-Dreifuss, facioscapulohumeral, oculopharyngeal, and limb-girdle muscular dystrophies [1]. Muscular dystrophies of Duchenne (DMD) and Becker (DMB) were the common. Each disorder varies in severity, age of onset, pattern of inheritance, and affected muscle groups and other organs [2]. Crude prevalence per 100,000 for all muscular dystrophies across the included studies ranged between 3.8 in Japan to 26.8 in Egypt [3,4]. Prognosis varies across the muscular dystrophies with some patients experiencing mild, though usually progressive symptoms, while others experience severe disability and early mortality [1]. Muscular dystrophies are ubiquitous pathologies that affect all continents but particularly affect certain populations in Maghreb [5,6], Asia [7], America and in Scandinavian countries [8,9]. There are relatively few investigations in Africans. The most studies were done in South Africa. There are no more studies regarding the prevalence of muscular dystrophy in Burkina Faso. The objective of our study is to give the experience of Burkina Faso in the management of Muscular Dystrophies.

\section{Patients and Methods}

\section{Area of Study}

Burkina Faso is a country of West Africa which occupies an area of 274,300 K msq for a population of 16,248,558 according to the 2006 Burkina population census. This study was performed at the Neurology Department of Yalgado Ouedraogo Teaching 
Hospital January 2004 to December 2014 (10years), a tertiary national referral center for neurological disorders.

\section{Participants}

Seventeen patients with clinical diagnosis of myopathies (presence of proximal weakness, elevation of serum creatine kinase and the history of disease) were including retrospectively in the study. All patients included in this study were examined by neurologists. The history included onset of illness, distribution of weakness, atrophy, hypertrophy, course of the disease and family history. Muscle involvement was evaluated clinically using MRC grading scale.

Routine blood investigations and CK level were done in all. Muscle biopsy, muscle imaging immunohistochemistry and genetic diagnosis were done in certain patients. Molecular and genetic diagnosis was carried out in a reference laboratory in France. Patients with acute polymyotitis were non- in the study

\section{Data Collection and Analysis}

The analysis concerned Sociodemographic features of the study population (age, sex, residence, profession), clinical features (past medical history of epilepsy or not. We collected and analyzed epidemiological, clinical data using the Sphinx 5.0 software. Incomplete records were not included in the study. The confidentiality of the data was preserved by the anonymity of the fact sheets.

\section{Ethical Considerations}

We preserved the anonymity of all patients included in the study.

\section{Results}

Out of 17 patients, 16 (94.2\%) were men and one (5.8\%) woman. The mean age of patients was 19.82 years (6-39 years). The population adult older than 15 years was 14 (82.3\%) patients. Fifteen patients were coming from urban regions and 5 from rural areas. Table 1 describes sociodemographic features of 17 patients with Muscular dystrophies. The mean age at disease onset was 6.7 years (ranges 3 years-25 years). Muscular dystrophy age of onset was between 5-10 years in 9 (52.9\%) patients followed by 0-5 years in $4(23.5 \%)$ patients. Only $11.7 \%(n=2)$ of the patients had age of onset at $25-30$ years of age. Overall, $11.7 \%(n=8)$ of the patients had consanguineous parents. Eight (47\%) patients had family history of similar cases. Disease onset was characterized by motor retardation in $10(58,8 \%)$ patients, difficulties in walking in 8 (47\%) patients and difficulties in running in 7 (41.1\%) patients. The mean age of patients at the first visit was 10.94 years (Ranges 5-26 years). The patients presented at 5-10 years of age in $5(29.4 \%)$ patients, between $10-15$ years in 7 (41.1\%) patients, between $15-20$ years in one (5.8\%) patient and between $25-30$ years in $4(23.5 \%)$ patients. The interval from the age of onset to the time the patient first presented (disease duration) was 9.41 years. The Table 2 describes the interval from the age at onset to age at first visit. At first visit, muscle weakness started proximally and had selective symmetrical distribution in the upper and lower limbs in 16 (94.1\%) patients. One (5.8\%) patients had lost the walk before first visit (patient 1).

\begin{tabular}{|l|l|}
\hline Demographic features & Number $\mathbf{( \% )}$ \\
\hline Mean age & 19.82 years \\
\hline Age ( years) & \\
\hline $5-10$ & $2(11.7 \%)$ \\
\hline $11-15$ & $3(17.6 \%)$ \\
\hline $16-20$ & $7(41.1 \%)$ \\
\hline$>20$ & $5(29.4 \%)$ \\
\hline Male gender & $16(94.1 \%)$ \\
\hline Pediatric patients & $12(70.5 \%)$ \\
\hline Urban residence (\%) & $15(88.2 \%)$ \\
\hline Consanguineous family & $2(11.7 \%)$ \\
\hline Familial case & $8(47 \%)$ \\
\hline
\end{tabular}

Table 1: Sociodemographic features of 17 patients with muscular dystrophies

There was no systematic psychometric tests were done for the patients, but informal assessment revealed normal language function. There was not evident symptomatic cardiac involvement. The Table 3 describes the clinical data of muscular dystrophy patients at the first visit. The most clinical phenotype was Duchenne muscular dystrophy (52.9\%) followed by Becker muscular dystrophy (41.1\%) and Limb girdle muscular dystrophy (5.8\%). According to biochemical features, serum creatine kinase level (CK) was elevated in the whole patients. The mean CK level was $3016.64 \mathrm{U} / \mathrm{l}$ (range 344 - $8896 \mathrm{U} / \mathrm{l}$ ), normal value for our laboratory $<150 \mathrm{U} / \mathrm{l}$. Nine patients $(52.9 \%)$ patients had done genetic testing and immunohistochemical analysis. The diagnostic 


\begin{tabular}{|l|l|}
\hline Clinical features & Number $=\mathbf{1 7}$ \\
\hline Motor deficit, $\mathrm{n}(\%)$ & $16(91.1)$ \\
\hline Gower's sign, $\mathrm{n}(\%)$ & $15(88.2)$ \\
\hline Proximal amyotrophy, $\mathrm{n}(\%)$ & $10(58.8)$ \\
\hline Distal amyotrophy, $\mathrm{n}(\%)$ & $9(52.9)$ \\
\hline Scapula alata, $\mathrm{n}(\%)$ & $7(41.1)$ \\
\hline Calf hypertrophy, $\mathrm{n}(\%)$ & $5(29.4)$ \\
\hline Cachexia, $\mathrm{n}(\%)$ & $3(17.6)$ \\
\hline Cognitive impairment, $\mathrm{n}(\%)$ & $1(5.8)$ \\
\hline Cardiac deterioration, $\mathrm{n}(\%)$ & $1(5.8)$ \\
\hline Orthopedic deterioration, $\mathrm{n}(\%)$ & $7(41.1)$ \\
\hline Loss of walk, n (\%) & $1(5.8)$ \\
\hline
\end{tabular}

Table 2: clinical features of Muscular dystrophy patients at the first visit

of muscular dystrophies was confirmed in 5 patients (55.5\%). Immunostaining showed evidence of pattern for dystrophin in 3 cases, dysferlin in one case and congenital myopathy in another one case. Genetic testing had found duplication of exons 3 and 4 in Dystrophin gene one case, deletion of exons 48 to 52 in two cases and absence of duplication and deletion in 2 cases. Deletions and duplications were reported in the Dystrophin gene. The confirmed diagnosis was DMD in 2 cases, BMD in one case, dysferlinopathie (one case) and congenital dystrophy in another one case. During study period, patients had benefited of three pluridisciplinary consultations with neurologist, pediatric pneumologist and cardiologist. The number of pluridisciplinary consultation was 2.52 per patient and 14 patients had done more than one consultation. During this follow up, 8 (47\%) patients had deterioration and $2(11.1 \%)$ had stopped their follow-up without medical advice. In totality, loss of the ability to walk was observed in 4 (23.5\%) patients, respectively before the follow up (patient 1) and during the follow up (patient 4, 5 and 6). The mean age when last walked was 14.25 years. Patients had loss the walk respectively at the age of 24 years (patient 1 ), 14 years (patient 4), 10 years (patient 5) and 9 years (patient 6). Cardiovascular deterioration occurred in 5 (29.4\%) at the age of 18 years (patient 1,4,6,7 and 11). The cardiovascular abnormalities was represented by decline in left ventricular (LV) systolic function and left ventricular hypertrophy respectively in 2 patients. Ventricular arrhythmias were seen on electrocardiogram in only one patient. \%). Orthopedic deterioration was observed in 7 (41.1\%) patients. Scoliosis, hyperlordosis, equinovarus and kyphosis were seen respectively in 2 patients. Death was observed in an 18-year-old boy who had cardiac and respiratory deterioration (patient 4). The Table 3 describes the deterioration in patients with muscular dystrophies. According to treatment, all the patients with muscular dystrophies had received physiotherapy. Corticosteroid was prescribed in 7 (41.1\%) patients and angiotensin-converting enzyme inhibitors (ACE) in one (5.8\%) patient Table 4. All this treatment was only used in patients with DMD and BMD. The Table 5 summarizes the demographic and clinical features of patients with muscular dystrophies.

\begin{tabular}{|c|c|}
\hline Interval onset and first visit ( years) & Population study $(\mathbf{N}=\mathbf{1 7})$ \\
\hline $0-5$ & 15 \\
\hline $5-10$ & 0 \\
\hline $10-15$ & 1 \\
\hline $15-20$ & 0 \\
\hline $21-25$ & 1 \\
\hline \multicolumn{2}{|c|}{ Table 3: Interval between onset and first visit (year) }
\end{tabular}

\begin{tabular}{|c|c|}
\hline Deterioration & Number (\%) \\
\hline Loss of walk & $4(23.5 \%)$ \\
\hline Arrhythmia & $2(11.7 \%)$ \\
\hline Cardiomyopathy & $2(11.7 \%)$ \\
\hline Cardiac insufficiency & $1(5.8 \%)$ \\
\hline Scoliosis & $2(11.7 \%)$ \\
\hline Lordosis & $2(11.7 \%)$ \\
\hline Foot varus & $2(11.7 \%)$ \\
\hline Kyphosis & $2(11.7 \%)$ \\
\hline Death & $1(5.8 \%)$ \\
\hline
\end{tabular}

Table 4: Clinical outcome of patients with muscular dystrophies $(\mathrm{N}=17)$ 


\begin{tabular}{|c|c|c|c|c|c|c|c|c|c|c|c|}
\hline $\begin{array}{l}\text { Patient } \\
\mathrm{N}^{\circ}\end{array}$ & $\begin{array}{c}\text { Age } \\
\text { at onset } \\
\text { (years) }\end{array}$ & $\begin{array}{c}\text { Age at } \\
\text { first visit } \\
\text { (years) }\end{array}$ & $\begin{array}{c}\text { Age at } \\
\text { inclusion } \\
\text { ( years) }\end{array}$ & Sex & $\begin{array}{l}\text { Family } \\
\text { cases }\end{array}$ & Consanguinity & $\begin{array}{l}\text { Clinical } \\
\text { features }\end{array}$ & $\begin{array}{l}\text { CK } \\
\text { level }\end{array}$ & $\begin{array}{l}\text { Genetic } \\
\text { testing }\end{array}$ & $\begin{array}{c}\text { Molecular } \\
\text { diagnosis }\end{array}$ & Complication \\
\hline 1 & 11 & 26 & 34 & M & None & No & BMD & 1526 & $\begin{array}{l}\text { Duplication of } \\
\text { exons } 3 \text { and } 4\end{array}$ & BMD & $\begin{array}{c}\text { Loss of walk } \\
\text { Cardiopathy scoliosis }\end{array}$ \\
\hline 2 & 5 & 27 & 39 & M & None & Yes & BMD & 1765 & N/A & N/A & None \\
\hline 3 & 13 & 17 & 25 & M & None & No & BMD & 725 & $\mathrm{~N} / \mathrm{A}$ & $\mathrm{N} / \mathrm{A}$ & None \\
\hline 4 & 6 & 9 & 18 & M & 1 & No & DMD & 987 & $\begin{array}{l}\text { Duplication of } \\
\text { exons } 3 \text { and } 4\end{array}$ & DMD & $\begin{array}{l}\text { Loss of walk, cardi- } \\
\text { opathy, respiratory, } \\
\text { scoliosis, death }\end{array}$ \\
\hline 5 & 5 & 8 & 15 & M & None & No & DMD & 2141 & N/A & N/A & $\begin{array}{l}\text { Loss of walk, } \\
\text { kyphosis }\end{array}$ \\
\hline 6 & 3 & 7 & 15 & M & None & No & DMD & 1815 & $\begin{array}{c}\text { No deletion or } \\
\text { duplication of exon }\end{array}$ & CMD & $\begin{array}{c}\text { Loss of walk, } \\
\text { cardiopathy kyphosis }\end{array}$ \\
\hline 7 & 7 & 10 & 15 & M & None & No & DMD & 3345 & $\begin{array}{l}\text { Deletion of exons } \\
\quad 48 \text { to } 52\end{array}$ & DMD & Cardiopathy lordosis \\
\hline 8 & 8 & 10 & 16 & M & 3 & Yes & DMD & 1925 & N/A & N/A & Foot varus \\
\hline 9 & 3 & 6 & 10 & M & 3 & No & DMD & 3754 & N/A & N/A & None \\
\hline 10 & 9 & 11 & 18 & M & None & No & BMD & 4825 & N/A & N/A & Lordosis \\
\hline 11 & 21 & 25 & 29 & M & 1 & No & BMD & 8896 & $\begin{array}{c}\text { No deletion or } \\
\text { duplication of exon }\end{array}$ & LMGD 2B & $\begin{array}{l}\text { Cardiopathy foot } \\
\text { varus }\end{array}$ \\
\hline 12 & 8 & 10 & 12 & M & 3 & No & DMD & 4634 & N/A & N/A & None \\
\hline 13 & 9 & 11 & 18 & M & 4 & No & DMD & 834 & N/A & N/A & None \\
\hline 14 & 5 & 5 & 6 & $\mathrm{~F}$ & None & No & DMD & 2565 & N/A & N/A & None \\
\hline 15 & 9 & 12 & 18 & M & None & No & BMD & 7475 & $\mathrm{~N} / \mathrm{A}$ & N/A & None \\
\hline 16 & 8 & 12 & 20 & M & 2 & No & BMD & 1975 & N/A & N/A & None \\
\hline 17 & 25 & 26 & 27 & M & None & No & LGMD & 2096 & N/A & N/A & None \\
\hline
\end{tabular}

Abbreviations : M : male, F : female, DMD: Duchenne muscular dystrophy, BMD: Becker muscular disease, CMG : Congenital muscular dystrophy, LGMG : Limb girdle muscular dystrophy , CK: Serum creatine kinase, N/A : no available

Table 5 : Demographic and clinical features of patients with muscular dystrophies

\section{Discussion}

This study demonstrate that muscular dystrophies was present in African black, as reported in 17 patients in Burkina Faso. The few number of patients included in the study is in consistence with others studies carried in West Africa [6,7]. The number of cases is probably underestimated in our case. The majority of patients were coming from urban areas (88\%) in which there are health workers (neurologists, pediatrician) able to care neuromuscular diseases. Patients who were coming from urban areas had been referred by a local association of myopathy which explains that they are specialized health care access. In rural areas, there are specially a lack of knowledge of disease by health workers and ignorance of patients. Knowledge could be disseminated towards caretakers, physicians (neurologists, pediatricians, general patricians) and paramedical staff by continuous medical training, advanced training course in the neurology department. Indeed, build a local/national network of specialist and patient registry is an opportunity for us. The diagnosis based on CPK level is not available in rural zone. Currently there are 3 specialists on muscular dystrophies (composed of 2 neurologists and one anatomopathologist) in Burkina Faso for a population of 16 millions of persons. There is a weekly consultation for muscular dystrophy in the neurology department. For next years, it is necessary to have more consulations in neurology department in the main hospital of Ouagadougou and to make screening campaigns in rural areas. The mean age at disease onset was 6.7 years (ranges 3 years-25 years), in line with Dey et al. and Swaminathan et al. who observed respectively an average age at onset at 3.9 years and 3.1 years $[9,10]$. In contrast, Manjunath $M$ et al. had found that age at onset mean was 45.3 years [11]. The majority of our patients (52.9\%) had disease onset at the age between 5-10 years while Viswajyothi in India observed that $50 \%$ of patients had disease onset between the ages of 0-5 years [12]. Thus, muscular dystrophy is seen in early childhood. The majority of our population studied were male (94.2\%), in line with the study of Viswajyothi P et al. in India which report that $90 \%$ of this study population was men [12]. This study showed that the diagnosis of muscular dystrophy was tardy at the age 10.94 years. The majority of patients presented at the age between 10-15 years (41.1\%) patients, in line with Viswajyothi P in India who observed the same result. The first symptoms at onset are not recognizing by families as muscular features and are unknown by most of the health agents. Consanguinity was observed in 12 percent of our patients. In $\mathrm{X}$-linked diseases consanguineous marriage was detected in $28.1 \%$ of patients with DMD [13]. Consanguinity is widely practiced in countries of Asia and Africa especially in societies where Islam prevails [14]. Forty seven percent of patients had family history of similar cases. People with a family history of muscular dystrophy are at a higher risk of developing the disease or passing it on to their children. The most clinical phenotypes were Duchenne muscular dystrophy (52.9\%), Becker muscular dystrophy (41.1\%) 
and Limb girdle muscular dystrophy (5.8\%). In terms of the prevalence of dystrophy types, our results are consistent with the results of Khadijeh et al. in Iran and Paul in the United States which showed the higher prevalence of Duchenne dystrophy than Becker dystrophy in the United States $[15,16]$. Some different methods can be used to diagnose the various types of muscular dystrophy, such as a Serum creatine kinase (CPK) test, an electromyography (EMG) test, a nerve conduction velocity (NCV) test, a genetic test, and a muscle biopsy. In our study, electromyography is not available for muscular dystrophies. Muscle biopsy was done in only one patient because it was not practical in Burkina Faso. Serum CK level was assessed and elevated in all our patients. This investigation is only available in two towns of Burkina Faso, Ouagadougou, the capital city and Bobo Dioulasso. An epidemiological study by El-Tallawy et al. on muscular dystrophies in Egypt found that more than $80 \%$ of subjects had an elevated CPK (> 225 IU/l) [4], which is consistent with our results, which showed elevated CPK in about $88.8 \%$ of patients and constitute with clinical findings the key of the diagnosis [17]. In our study, the diagnosis of Muscular dystrophy was confirmed in about $42 \%$ of cases by molecular genetic testing. According to Alao et al. [18], the diagnosis of muscular dystrophy was confirmed by molecular genetic testing in Benin, Niger and Guinea respectively in 50\%, $28 \%$ and $0 \%$ of blood samples. In our study, deletions and duplications have been reported in the dystrophin gene in tree patients with Duchenne and Becker muscular dystrophy. Only one patient had deletion in dysferlin gene. Dystrophin gene was reported in African patients with Duchenne in Ghana [19], in Rwanda and South Africa [6,20,21]. In our study, the confirmed diagnosis was DMD in 2 cases, BMD in one case, dysferlinopathie (one case) and congenital dystrophy in another one case. In opposition with the study of Alao, we did not found any case of Gamma sarcoglycanopathy, spinal amyotrophic or Becker Myotony. To improve diagnosis and care in our context, it is we must facilitate the availability of a genetic and molecular screening device, access to paraclinical assessments (biopsies, muscle imaging) and promote medical center equipment (EMG, needed for biopsies, etc.). To date, no effective treatment is available to patients with muscular dystrophy. In our study, corticosteroids and ACE and were used for symptomatic treatment respectively $41.1 \%$ and 5.6 in patients with DMD and BMD. Corticosteroids are useful to improve muscle strength and function in the short-term (six months to two years), especially in DMD. In addition, ACE inhibitors were useful in the management of cardiomyopathy in patients with Duchenne or Becker muscular dystrophy [22]. If we considered the number of patients with clinical features of DMD or BMD, corticosteroids and ACE were less used. This situation could be explained by high cost of these treatments. Physiotherapy was used in all patients but was limited by orthopedic complications (41.1\%). The short duration of this treatment was observed in patients who had financial constraints. To facilitate access to specific treatments, we should provide g corticosteroid treatment, electric wheelchairs and inclusion of patients in clinical studies. The mortality rate (5.8\%) can be explained by the severity of complications, including cardiac deteriorations [23].

\section{Limits of the Study}

This was a retrospective case-note review. Some data were missing from clinical notes, in particular information about consanguinity. This may reflect difficulty in asking families about this issue in a clinic setting, or poor documentation, but it did restrict analysis of this variable. Even though this was a full population study, the specific conditions being studied are rare and numbers in individual diagnostic groups were small, which limited the power to undertake more detailed analysis. As it is a prevalence study, it was only possible to assess association rather than causation.

\section{Conclusion}

The present study revealed that Muscular Dystrophy is not an uncommon disease in Burkina Faso. We have concluded that if clinical diagnosis is possible nevertheless some difficulties exist to do muscles biopsy analysis. Physiotherapy and prevention of cardiac deterioration are available in our context.

\section{References}

1. Mercuri E, Muntoni F (2013) Muscular dystrophies. Lancet 381: 845-60.

2. Mercuri E, Muntoni F (2013) Muscular dystrophy: new challenges and review of the current clinical trials. Curr Opin Pediatr 25: 701-7.

3. Nakagawa M, Nakahara K, Yoshidome H, Suehara M, Higuchi I, et al. (1991) Epidemiology of progressive muscular dystrophy in Okinawa, Japan. Classification with molecular biological techniques. Neuroepidemiology 10: 185-91.

4. El-Tallawy HN, Khedr EM, Qayed MH, Helliwell TR, Kamel NF (2005) Epidemiological study of muscular disorders in Assiut, Egypt. Neuroepidemiology 25: 205-11.

5. Topaloglu H (2013) Epidemiology of muscular dystrophies in the Mediterranean area. Acta Myol 32: 138-41.

6. Ballo R, Viljoen D, Beighton P (1994) Duchenne and Becker muscular dystrophy prevalence in South Africa and molecular findings in 128 persons affected. S Afr Med J 84: 494-7.

7. Meilleur K G, Coulibaly S, Traoré M, Landouré G, La Pean A, et al. (2011) Genetic testing and counseling for hereditary neurological diseases in Mali. J Community Genet 2: 33-42.

8. Chung B, Wong V, Ip P (2003) Prevalence of neuromuscular diseases in Chinese children: a study in southern China. J Child Neurol 18: 217-9.

9. Dey S, Senapati AK, Pandit A, Biswas A, Guin DS, et al. (2015) Genetic and clinical profile of patients of Duchenne muscular dystrophy: experience from a tertiary care center in Eastern India. Indian Pediatr 52: 481-4.

10. Swaminathan B, Shubha GN, Shubha D, Murthy AR, Kiran Kumar HB, et al. (2009) Duchenne muscular dystrophy: a clinical, histopathological and genetic study at a neurology tertiary care center in Southern India. Neurol India 57: 734-8. 
11. Manjunath M, Kiran P, Preethish-Kumar V, Nalini A, Singh RJ, et al. (2015) A comparative study of mPCR, MLPA, and muscle biopsy results in a cohort of children with Duchenne muscular dystrophy: a first study. Neurol India 63: 58-62.

12. Viswajyothi P, Rambabu MV (2018) Profile, types, duration and severity of muscular dystrophy: a clinical study at a tertiary care hospital. Int J Adv Med 5: 700-4.

13. Shawky RM, Elsayed SM, Zaki ME, Nour El-Din SM, Kamal FM (2013) Consanguinity and its relevance to clinical genetics. The Egyptian Journal of Medical Human Genetics 14: 157-64.

14. Ali A, Zahad S, Masoumeh A, Azar A (2008) Congenital malformations among live births at Arvand Hospital, Ahwaz, Iran - a prospective study. Pak J Med Sci 24: 33-7.

15. Tehrani KHN, Hajiloo M, Asadollahi E, Lagini FP (2018) Prevalence of muscular dystrophy in patients with muscular disorders in Tehran, Iran. Eur J Transl Myol 28: 7380.

16. Romitti PA, Zhu Y, Puzhankara S, James KA, Nabukera SK, et al. (2015) Prevalence of Duchenne and Becker muscular dystrophies in the United States. Pediatrics 135: 513-21.

17. PB Andersson, Rando TA (1999) Neuromuscular disorders in childhood. Curr Opin Pediatr 11: 497-503.

18. Alao MJ, Lalya F, Adjien C, Adjagba M, Azombakin S (2017) Diagnosis of myopathies in West Africa: experience of four countries. Cah Myol 15: 66-7.

19. Peddareddygari LR, Pillai BH, Nochlin D, Sharer LR, Grewal RP (2011) Phenotype genotype analysis of dystrophinopathy caused by duplication mutation in Dystrophin gene in an African patient. Afr Health Sci 11: 607-9.

20. Uwineza A, Hitayezu J, Murorunkwere S, Ndinkabandi J, Kalala Malu CK, et al. (2014) Genetic diagnosis of Duchenne and Becker muscular dystrophy using multiplex ligation-dependent probe amplification in Rwandan patients. J Trop Pediatr 60: 112-17.

21. Ballo R, Viljoen D, Beighton P (1994) Duchenne and Becker muscular dystrophy prevalence in South Africa and molecular findings in 128 persons affected. S Afr Med J 84: 494-7.

22. Hallwirth Pillay KD, Bill PL, Madurai S, Mubaiwa L, Rapiti P (2007) Molecular deletion patterns in Duchenne and Becker muscular dystrophy patients from KwaZulu Natal. J Neurol Sci 252: 1-3.

23. Silva MC, Magalhães TA, Meira ZM, Rassi CH, Andrade AC, et al. (2017) Myocardial fibrosis progression in Duchenne and Becker muscular dystrophy: A randomized clinical trial. JAMA Cardiol 2: 190-99. 